\title{
Talo-calcaneal distraction Ilizarov frame: an ergonomic method to manage intra-articular fractures of calcaneum
}

\author{
Anoop Raj Singh', Javed Ahmad ${ }^{2}$, Vivek Kumar Shrivastava ${ }^{3}$, Pavneesh Kumar ${ }^{4}$ \\ ${ }^{1}$ Assistant Professor, Department of Orthopedics, SMMH Medical College, Saharanpur, Uttar Pradesh, India, \\ ${ }^{2,3}$ Assistant Professor, Department of Orthopedics, Mahamaya Rajkiya Allopathic Medical College, Ambedkar Nagar, \\ Uttar Pradesh, India, SMMH Medical College, Saharanpur, Uttar Pradesh, India, ${ }^{4}$ Assistant Professor, Department of \\ Orthopedics, Government Doon Medical College Dehradun, India
}

Background: Principle of distraction and an indirect reduction was used to promote healing of fractures and adequate regeneration of cartilage at the subtalar joint. Aims and Objectives: The study was aimed to elaborate and develop role of Ilizarov as an alternative biological method to manage intraarticular fracture calcaneum with minimal chances of infection. Materials and Methods: Twenty-one patients were studied and the mean age of patients was 40.7 years (span: 20 to 65 years). Sanders CT classification was used to divide into type II, 11 (52.38\%); type III, 7 (33.33\%) and type IV, $3(14.28 \%)$. The average follow-up was 17.2 months (range: 6 to 24 months). AOFAS scale for ankle and hindfoot was used for assessment of patients- $7(33.33 \%)$ excellent, $7(33.33 \%)$ good, $3(14.28 \%)$ fair, and 4 $(19.04 \%)$ poor results. The average score was $81.5 \pm 12.1$. The mean period of treatment was 12 weeks (10 to 14 weeks). Results: On radiological assessment, Bohler's angle change was $19.7 \pm 4.4$ degrees to $33.51 \pm 5.7$ degrees; angle of Gissane changed from $126.4 \pm 6.7$ degrees preoperatively to $124.9 \pm 6.9$ degrees postoperatively; calcaneal height changed $40.14 \pm 1.98 \mathrm{~mm}$ preoperatively to $43.33 \pm 1.87 \mathrm{~mm}$ and width changed $45.09 \pm 3.65$ $\mathrm{mm}$ preoperatively to $43.09 \pm 3.16 \mathrm{~mm}$ postoperatively and reduction mal-alignment $>10$ degrees in 5 patients. Superficial skin infection at wire insertion sites was the most common complication encountered in our cases. Conclusion: Our results with this ergonomic technique in a small number of 21 non-randomised cases with a mean follow-up of 17.2 months attribute towards an alternate surgical substitute to conventional open reduction techniques in the treatment of intra-articular fractures of calcaneum having lesser rate of complications.
Access this article online

\section{Website:}

http://nepjol.info/index.php/AJMS

DOI: 10.3126/ajms.v12i7.35459

E-ISSN: 2091-0576

P-ISSN: 2467-9100

Copyright (c) 2021 Asian Journal of Medical Sciences

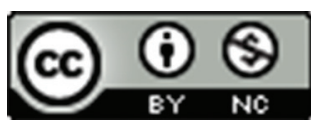

This work is licensed under a Creative Commons Attribution-NonCommercial 4.0 International License.

Keywords: Ilizarov; Distraction; Calcaneal fracture; Bohler's angle; Subtalar arthritis

\section{INTRODUCTION}

Of all the fractures encountered in orthopaedics, fractures of calcaneum constitute $2 \%$ with having an intra-articular displacement in 60 to 75 out of 100 patients. ${ }^{1,2}$ The modern era of surgical revolution had devised many innovative techniques to reduce complications and improve patient outcomes but the management of fractures like calcaneum are still facing the heat of controversy regarding how to classify them? Whether to do open reduction followed by internal fixation or use hybrid techniques of indirect reduction using various external fixation methods?. Non-operative treatment has lesser complications but more chances of progressive subtalar arthritis while operative treatment has an incidence of greater anatomical recovery. ${ }^{3-7}$ Palmer and Essex Lopresti had in their studies demonstrated the need for adequate reduction of these fractures, with inadequate reduction leading to poor results. ${ }^{8,9}$ Restoration of the subtalar joint is also crucial. The per-operative and post-operative complications are cited as one reason to oppose operative treatment. ${ }^{10}$ Applying distraction force using the percutaneous approach 
is one of the oldest surgical treatment for intra-articular fractures of oscalcis. ${ }^{11-13}$ Using Ilizarov as a distraction device at the talocalcaneal joint and reducing subtalar joint with the closed procedure could reduce the risk of complications associated with open reduction and internal fixation procedures. ${ }^{13,14}$ In this study, the clinical and radiological outcome of management of intraarticular calcaneal fractures using Ilizarov talocalcaneal frame (also known as KIR PAT'S STAC FRAME) is analysed.

\section{MATERIAL AND METHODS}

This is a prospective study including 21 intra-articular oscalcis fractures in 21 patients treated from March 2018 to March 2020 with indirect reduction and talocalcaneal Ilizarov frame. There were 18 males and 3 females, with a mean age of 40.7 years (span: 20 to 65 years). No patient had history of any chronic illness like uncontrolled diabetes mellitus, chronic renal failure. 11 fractures $(52.38 \%)$ resulted from fall from a height, 10 fractures $(47.6 \%)$ from road traffic accidents; having 3 as open fractures (Gustilo Anderson type 1), and other 5 with skin blisters due to raised compartment pressure. Plain radiographs of the ankle (anteroposterior (AP), lateral views and a Harris axial view), and computed tomography (CT) scans were gathered. Sanders CT classification system $^{4}$ was used to classify fractures into $11(52.38 \%)$ type II, 7 (33.33\%) type III, and $3(14.28 \%)$ type IV. Type I was excluded from the study. Approval was obtained from the Institutional Ethics Committee prior to the commencement of the study.

\section{Inclusion criteria}

1. Intraarticular calcaneal fracture Type II, III, and IV

\section{Exclusion criteria}

1 Sanders Type I

2 Patients with bilateral oscalcis fractures

3 Patients with concomitant fractures in the same or other limb or spine

4 Open fractures other than Gustilo Anderson Type 1.

5 Patients with severe lacerated wounds

Patient management and the operative technique Patient with acute injuries was treated immediately after obtaining radiographs and CT scan; however, patients approaching with blisters and severe swelling were managed conservatively to wait for subsidence of swelling (considering the possibility for open reduction in the scenario of un attained satisfactory reduction).

Patients were managed by using the idea from the technique described by Kir Pat et al. ${ }^{14}$ Patients were operated on plain table without-on-the-table traction and pulley (Figure 1. A); manual reduction and techniques of indirect reduction were employed using tools like olive wires, $\mathrm{k}$ wires, and Steinmann pins followed by distraction using progressive Ilizarov construct.

In first step, two olive wires were placed in talus medially and laterally parallel to the subtalar joint in the coronal plane. The first olive wire is directed from anterolateral to the posteromedial direction to avoid malleolar/deltoid capture, the second olive wire is directed anteromedial to posterolateral orientation or parallel to first at the base of Talar neck (Figure 1. A). In second step, half ring attached anteriorly and wire tensioned up to $90 \mathrm{~kg}$ (Figure 1. B). Third step comprises putting Ilizarov wires in calcaneum, which may also include mitigation of elevated tuberosity and tendoachilles by using Steinmann pin/Kwire (Figure 2. D) and manipulation of any impacted fragments by using K-wire as a joystick. However, in a standard case without much elevated tuberosity or any impacted fragment we used 3 wires ; first and second one to correct varus, which were placed nearly parallel to talar wires and perpendicular to calcaneal length in axial view in anterior half and posterior half of calcaneum respectively (Figure 1.C), and the last one placed in same transverse plane but posterosuperior to first one and anterosuperior to second one, forming a rough isoceles triangle as seen from lateral side (Figure 1.D), this third wire helps to maintain reduction of sustentaculi and appear more arched in radiographs (Figure 3.D and 3.E). In next step, these 3 wires now were attached to another half ring, which can be

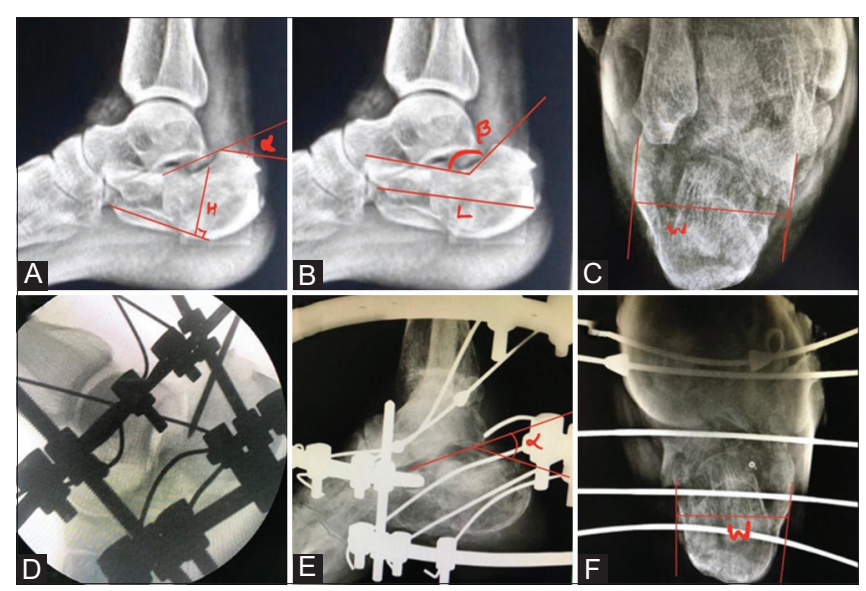

Figure 1: (A) Right ankle lateral view radiograph of a 45-year-old male depicting measurement of Bohler's angle(alpha) and calcaneal height $(\mathrm{H})$; Figure. $1(\mathrm{~B})$ Measurement of the critical angle of Gissane (beta) and calcaneal length (L); Figure. 1 (C) Axial view showing measurement of calcaneal width(W); Figure. 1 (D) per operative lateral image intensifier view showing subtalar distraction and manipulation of tuberosity using 3mm k-wire as a joystick; Figure. $1(E) \&(F)$ Three month follow up radiograph of the same patient showing Böhler's angle and consolidation of fractures and in axial view reduction of the width of the calcaneum 
attached to previously applied half ring through small rods. In the final step, subtalar distraction was applied under image intensifier (Figure 1.E and 2.E). The reduction was then confirmed using lateral, axial and broden's views taking maximum care to avoid any misinterpretation due to superimposition by rings. Since Ilizarov is a customizable implant, other permutations and combinations can be tried according to fracture geometry using distraction technique for example calcaneocuboid joint reduction can be addressed using more wires in metatarsals too. Considering the limitations of this technique, special attention should be given to the posterior facet of subtalar joint which is quite unforgiving owing to large number of

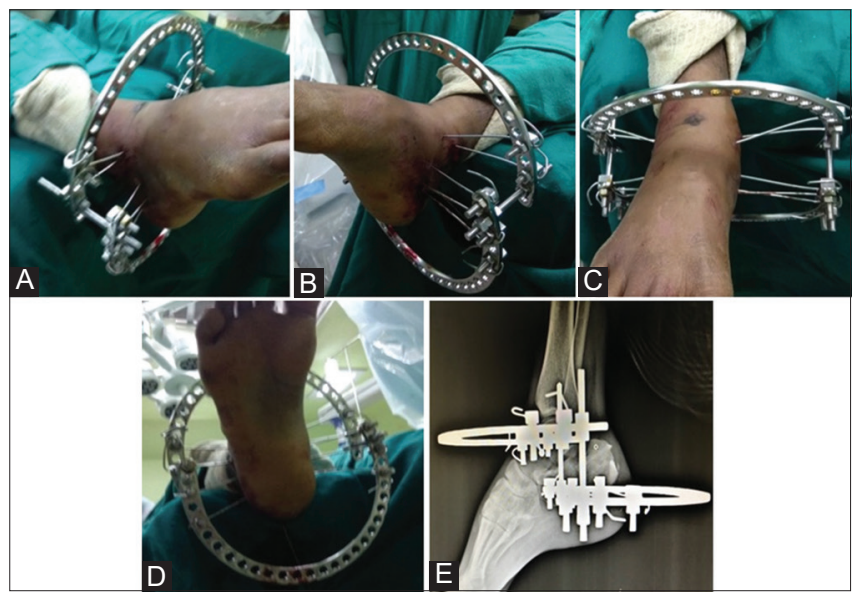

Figure 2: (A), (B), (C) \& (D) Immediate postoperative pictures showing talocalcaneal frame (KIR PAT'S FRAME), three llizarov wires in calcaneum and 2 olive wires in talus using two half rings to build the assembly; Figure. 3 (E) lateral radiograph of the same patient depicting assembly and reduction of fracture with subtalar distraction

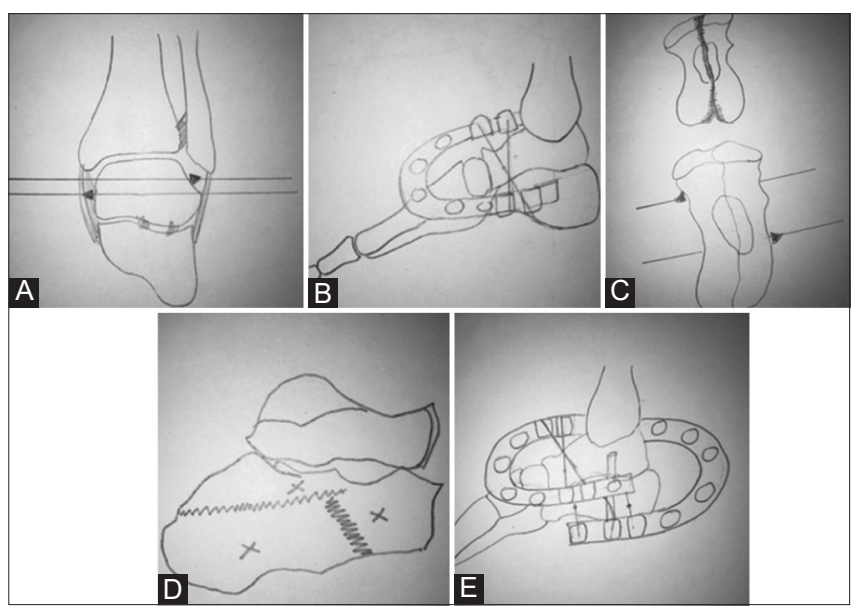

Figure 3: (A) showing step 1 with two olive wires placed in talus medially and laterally parallel to subtler joint; Figure 2. (B) second step showing half ring attached anteriorly; Figure 2. (C) wires in anterior and posterior half of calcaneum perpendicular to its axis maintaining varus as well as width of calcaneum; Figure 2. (D) lateral diagrammatic representation showing placement of wires in a hypothetical calcaneum fracture forming rough isosceles triangle; Figure 2. (E) formation of final frame by attaching two half rings and giving distraction at talocalcaneal joint forces converging on it and open reduction as a backup must be kept ready.

\section{Follow-up}

Limb elevation and active toe movements, active ankle and knee movements were immediately started as tolerated by patients. Mean admission time was 3 days during which intravenous antibiotics were given. Wire site dressing was done on alternate days using normal saline and local antiseptic and taught to patients for home-based care. Toe touch weight bearing with walker support started within the first week and partial weight-bearing on toes as tolerated by patients within 3 weeks. Clinical and radiological follow-up was done every 3 weeks in the first 3 months then every 3 months till last follow up. Radiological assessment (using lateral and axial views) and clinical assessment comparing: pre and post-operative Bohler's angles; Gissane angles; calcaneal height and width; Varus in calcaneum and subtalar movements. AOFAS scale for ankle and hindfoot used for functional assessment at final follow up. ${ }^{15}$ Mean follow-up duration was 17.2 months (range, 6 to 24 months).

\section{RESULTS}

AOFAS scale for ankle and hindfoot ${ }^{15}$ was used for clinical assessment. There were $7(33.33 \%)$ excellent, 7 (33.33\%) good, $3(14.28 \%)$ regular/fair, 4(19.04\%) poor (Table 1). Seven patients were showing signs of subtalar arthritis radiologically and 3 of them calcaneocuboid joint arthritis as well. No arthritic changes were noted in the ankle joint at last follow-up. 2 patients who developed reflex sympathetic dystrophy treated with physiotherapy and oral medications showed an improvement, later on, 7 patients had residual oedema of the foot. Superficial wire site and tract infection diagnosed in 16 of 21 cases and treated with local antiseptic and local antibiotics without any case of deep infection. Eight patients complained of mild pain around the ankle and subtalar joint and 7 patients had residual heel pain, requiring silicone heel support for shoes and some minor adjustments in shoes but till follow-up, all patients returned to work. Range of motion of the subtalar joint as compared to the normal side was more than $75 \%$ in $9(42.8 \%)$ while, in the 9 $(42.8 \%)$, it was $25-75 \%$ and remaining three $(14.28 \%)$ had $<25 \%$. Ankle joint in all cases showed no signs of restriction of movement.

Comparing means as well as using t-test showed a significant increase in Bohler's angle in postoperative values compared to its preoperative values $(\mathrm{p}<0.0001)$; similarly angle of Gissane showed a significant increase $(\mathrm{p}<0.0001)$ compared to its preoperative values using same tests. The preoperative 
Table 1: Clinico-radiological results according to type of fracture

\begin{tabular}{|c|c|c|c|c|c|c|c|}
\hline \multirow{2}{*}{\multicolumn{2}{|c|}{$\begin{array}{l}\text { Sander's } \\
\text { classification }\end{array}$}} & \multicolumn{4}{|c|}{ Clinical results } & \multirow[t]{2}{*}{$\begin{array}{l}\text { Arthritis of } \\
\text { subtalar joint }\end{array}$} & \multirow[t]{2}{*}{$\begin{array}{c}\text { Arthritis of } \\
\text { Calcaneo-cuboid joint }\end{array}$} \\
\hline & & $\begin{array}{l}\text { Excellent } \\
(90-100)\end{array}$ & $\begin{array}{l}\text { Good } \\
(80-89)\end{array}$ & $\begin{array}{l}\text { Regular } \\
(70-79)\end{array}$ & $\begin{array}{l}\text { Poor } \\
(<69)\end{array}$ & & \\
\hline II & $11(52.38 \%)$ & $5(45.45 \%)$ & $5(45.4 \%)$ & 0 & $1(9.09 \%)$ & $1(9.09 \%)$ & 1 (9.09\%) \\
\hline III & $7(33.33 \%)$ & $2(28.5 \%)$ & $2(28.5 \%)$ & $2(28.5 \%)$ & $1(14.28 \%)$ & $3(42.8 \%)$ & $1(14.28 \%)$ \\
\hline IV & $3(14.28 \%)$ & 0 & 0 & $1(33.33 \%)$ & $2(66.6 \%)$ & $3(100 \%)$ & $1(33.3 \%)$ \\
\hline Total & 21 & $7(33.3 \%)$ & $7(33.3 \%)$ & $3(14.28 \%)$ & $4(19.04 \%)$ & 7 (33.33\%) & 3 (14.28\%) \\
\hline
\end{tabular}

and postoperative values of Bohler's angle showed a significant difference in all fracture types i.e., TYPE II and TYPE III, it is $\mathrm{p}<0.0001$ and in TYPE IV showing $\mathrm{p}<0.0008$. Calcaneal width decrease was not significant $(\mathrm{p}=0.06)$ but calcaneal height increase was statistically significant $(\mathrm{p}<0.0001)$, compared to preoperative values. Chi-square tests were done to identify the statistical correlation between clinical results denoted by AOFAS score and development of subtalar arthritis which showed $\mathrm{p}<0.0001$ which showed it is significant (as in our tests $\mathrm{p}<0.05$ is taken as significant); similarly, tests showed the correlation between fracture type (Sanders's classification) and subtalar arthritis as significant $(\mathrm{p}<0.0001)$.

\section{DISCUSSION}

The eternal debate regarding modalities of calcaneal fracture treatment persists. In our study, we tried to analyze the results of our principle of short segment capsuloligamentotaxis applying it to specific joints like subtalar or calcaneocuboid, while leaving the adjacent joints free allowing early return to function, with minimal disturbance of soft tissues or devascularization of bone. ${ }^{13}$ The intrinsic elasticity of the frame favors early union in cancellous bone, far earlier than static frames using plates and screws. Ligamentotaxis is now a well-documented procedure in orthopedics useful in many intra-articular fractures like distal femur, proximal tibia, distal tibia and distal radius. ${ }^{16-20}$

In our technique, we leveraged the ligaments spanning talus and calcaneum to achieve maximum subtalar and calcaneocuboid reduction and avoiding impingement of fracture fragments mainly the tibiocalcaneal part of the deltoid ligament, the talocalcaneal interosseous ligament(TCIL); cervical, anterior, lateral, medial and posterior talocalcaneal ligaments. ${ }^{11}$ Many recent studies which compared operative and non-operative or minimally invasive modalities of treatment for calcaneal fractures indicated comparable functional results with a lesser rate of infections in non-operative / minimally invasive treatment procedures. ${ }^{21-23}$ In our study there was no instance of deep infection, all the reported ones were superficial and healed with local treatment. However open reduction and internal fixation of calcaneum may be associated with a high rate of infection up to $25 \%,{ }^{24}$ Zwipp et al in $7.9 \%$ cases. ${ }^{25}$ Distraction and dynamization along with ankle motion lead to fewer incidences of contracture, stiffness of ankle and subtalar joint. Distraction also helps in healing of cartilaginous surface at involved joint hence fewer chances of developing subtalar arthritis, ${ }^{26}$ Subtalar arthritis may result from cartilage damage at time of injury due to irreversible high energy impact as depicted by Boreli et al. ${ }^{27}$ Zwipp et al reported subtalar arthritis in $>50 \%$ cases and calcaneocuboid joint arthritis in $>25 \%$ cases. ${ }^{28}$ In this study, radiological follow-up showed subtalar joint arthritic changes in $7(33.33 \%)$ of cases in correlation with sanders classification, 3 of type $1 \mathrm{~V}, 3$ of type III, 1 of type II showed these subtalar arthritic changes; 3 out of 7 showed both calcaneocuboid and subtalar arthritis.

Early movement and early partial weight-bearing didn't seem to adversely affect the patient outcome as observed by Hyer et al. ${ }^{29}$ Kienast et al, ${ }^{30}$ also shown that had protective effect against disuse osteoporosis and helpful in heeling fat pad desensitization thus preventing chronic heel pain as documented by Houghton et al. ${ }^{31}$ The early movement also helped in reducing the incidence of calcaneofibular impingement. Only-thin wire reduction technique prevented any incidence of Sural nerve injury or any iatrogenic neurovascular bundle injury. However, the study has certain drawbacks like - not following the strict three-point distraction technique on which it is loosely based; difficulty in raising the central fragment in Sanders III and Sanders 1V (as there is no mechanism to allow ligament-taxis there) ; difficulty in assessing the reduction intraoperatively (Broden's view to see all aspects of posterior facet could not be taken easily due to superimposed rings); post-operative collapse could not be factored in, intra and inter observer discrepancies along with lack of standardization of radiographs; a small sample of cases; lesser time of follow-up to study talocalcaneal joint arthritis and lack of control group. Therefore further improvement in technique like using radiolucent rings and going for open reductions by intraoperatively changing decision especially in cases of Sanders type1V fractures which had shown poor results with this technique; secondly, comparative long term studies are required to 
reach conclusive evidence of the utility of this technique in treating intra-articular calcaneal fractures.

\section{CONCLUSION}

To conclude we can say that this subtalar joint spanning Ilizarov frame is a useful device in treating intra-articular calcaneal fractures helping patients in gaining an early range of motion at foot and ankle joints, early weight-bearing with reduced incidence of subtalar arthritis especially in Sanders type II and type III. Ilizarov system is just a method like any other method, intended to provide stable retention of an accurately reduced fracture. However, the system will produce bad results in an inadequately reduced or improperly aligned fracture. Unlike internal fixations which are committed once the final stitch is applied, Ilizarov is a little more versatile, minor adjustments can be done in the outpatients' department, while a revisit to the operation theatre can even allow major adjustments without opening up the fracture site. This liberty does not however allow us to frame an improperly reduced fracture pattern.

\section{REFERENCES}

1. Lindsay WRN and Dewar FP. Fractures of the oscalcis. Am J Surg. 1958; 95:555-576. https://doi.org/10.1016/0002-9610(58)90438-0

2. Rowe $C R$, Sakellarides $H$, Freeman $P$ and Sorbie C. Fractures of oscalcis: A long term follow-up study of one hundred forty-six patients. JAMA. 1963; 184:920.

https://doi.org/10.1001/jama.1963.03700250056007

3. Leung KS, Yuen KM and Chan WS. Operative treatment of displaced intra-articular fractures of the calcaneum. Mediumterm results. J Bone Joint Surg. 1993; 73-B: 196-201. https://doi.org/10.1302/0301-620X.75B2.8444936

4. Sanders R. Intra-articular fractures of the calcaneus: present state of the art. J Orthop Trauma. 1992; 6: 252-265.

https://doi.org/10.1097/00005131-199206000-00022

5. Thermann $\mathrm{H}$, Hufner $\mathrm{T}$, Schratt $\mathrm{HE}$, Albrecht $\mathrm{K}$ and Tscherne $\mathrm{H}$. [Treatment of intraarticular calcaneal fractures in adults. A treatment algorithm.] (in German). Unfallchirurg.1999; 102: 152-166 https://doi.org/10.1007/s001130050388

6. Thordarson DB and Krieger LE. Operative vs nonoperative treatment of intra-articular fractures of the calcaneus: a prospective randomized trial. Foot Ankle Int.1996; 17: 2-9. https://doi.org/10.1177/107110079601700102

7. Tornetta P. Open reduction and internal fixation of the calcaneus using minifragment plates. J Orthop Trauma. 1996; 10: 63. https://doi.org/10.1097/00005131-199601000-00009

8. Palmer I. The mechanism and treatment of fractures of the calcaneus; open reduction with the use of cancellous grafts. $J$ Bone Joint Surg Am. 1948; 30: 2-8.

https://doi.org/10.2106/00004623-194830010-00002

9. Essex-Lopresti P. The mechanism, reduction technique, and results in fractures of the oscalcis. Br J Surg. 1952; 39: 395-419. https://doi.org/10.1002/bjs.18003915704
10. Griffin D, Parsons N, Shaw E, Kulikov Y, Hutchison C and Lamb SE. Operative versus non-operative treatment for closed, displaced, intra-articular fractures of the calcaneus: randomized controlled trial. BMJ. 2014; 349: g4483.

https://doi.org/10.1136/bmj.g4483

11. Schepers $T$ and Patka P. Treatment of displaced intra-articular calcaneal fractures by ligamentotaxis: current concepts' review. Arch Orthop Trauma Surg. 2009; 129:1677-1683. https://doi.org/10.1007/s00402-009-0915-8

12. Prakash L. Magic of Ilizarov. 2020 Fifth edition Indian Academy of Orthopaedic Surgeons (IAOS): ISBN :978-81-937797-7-4

13. Besch L, Waldschmidt JS, Daniels-Wredenhagen M, Varoga D, Mueller M, Hilgert RE, et al. The treatment of intra-articular calcaneus fractures with severe soft tissue damage with a hinged external fixator or internal stabilization: long-term results. J Foot Ankle Surg. 2010; 49(1):8-15. https://doi.org/10.1053/j.jfas.2009.07.019

14. Malizos KN, Bargiotas K, Papatheodorou L, Dimitroulias A and Karachalios T. The below-the-ankle circular frame: A new technique for the treatment of displaced calcaneal fractures. $J$ Foot Ankle Surg. 2006;45(5):295-299.

https://doi.org/10.1053/j.jfas.2006.06.005

15. Kitaoka HB, Alexander IJ and Adelaar RS. Clinical rating systems for the ankle-hind foot, mid foot, hallux, and lesser toes. Foot Ankle Int.1994; 15: 349-353. https://doi.org/10.1177/107110079401500701

16. Watson JT, Ripple S, Hoshaw SJ and Fhyrie D. Hybrid external fixation for tibial plateau fractures: clinical and biomechanical correlation. Orthop Clin North Am. 2002;33(1):199-209, ix. https://doi.org/10.1016/S0030-5898(03)00080-4

17. Oh JK, Hwang JH, Sahu D and Jun SH. Complications rate and pitfalls of temporary bridging external fixator in periarticular comminuted fractures. Clin Orthop Surg. 2011; 3: 62-68. https://doi.org/10.4055/cios.2011.3.1.62

18. Clyburn TA. Dynamic external fixation for comminuted intraarticular fractures of the distal end of the radius. J Bone Joint Surg Am. 1987;69(2):248-254. https://doi.org/10.2106/00004623-198769020-00012

19. Saleh M, Shanahan $G$ and Fern ED. Intra-articular fractures of the distal tibia: Surgical management by limited internal fixation and articulated distraction. Injury. 1993; 24-B: 37-40. https://doi.org/10.1016/0020-1383(93)90081-G

20. Murphy CP, D'Ambrosia R and Dabezies EJ. The small pin circular fixator for distal tibialpilon fractures with soft tissue compromise. Orthopaedics.1991; 14: 283-290.

21. Bruce $J$ and Sutherland A. Surgical versus conservative interventions for displaced intra-articular calcaneal fractures. Cochrane Database Syst Rev. 2013; 1: CD008628. https://doi.org/10.1002/14651858.CD008628.pub2

22. Buckley RE and Meek RN. Comparison of open versus closed reduction of intraarticular calcaneal fractures: A matched cohort in workmen. J Orthop Trauma. 1992; 6:216-222. https://doi.org/10.1097/00005131-199206000-00014

23. Buckley RE, Tough S, McCormack R, Pate G, Leighton R, Petrie $\mathrm{D}$, et al. Operative compared with nonoperative treatment of displaced intra-articular calcaneal fractures: A prospective, randomized, controlled multicenter trial. J Bone Joint Surg Am. 2002;84A:1733-1744. https://doi.org/10.2106/00004623-200210000-00001

24. Schepers T. The sinus tarsi approach in displaced intra-articular calcaneal fractures: A systematic review. Int Orthop. 2011; 35:697-703. 
https://doi.org/10.1007/s00264-011-1223-9

25. Zwipp $\mathrm{H}$, Tscherne $\mathrm{H}$, Thermann $\mathrm{H}$ and Weber T. Osteosynthesis of displaced intraarticular fractures of the calcaneus. Clin Orthop.1993; 290: 76-86

https://doi.org/10.1097/00003086-199305000-00011

26. Van Valburg $A A$, van Roermund $P M$, Lammens $J$, van Melkebeek J, Verbout AJ, Lafeber FP, et al. Can llizarov joint distraction delay the need for an arthrodesis of the ankle? A preliminary report. J Bone Joint Surg Br. 1995; 77:720-725 https://doi.org/10.1302/0301-620X.77B5.7559696

27. Borelli J Jr, Torzilli PA, Grigiene R and Helfet DL. Effect of impact load on articular cartilage:Development of an intra-articular fracture model. J Orthop Trauma. 1997; 11:319-326. https://doi.org/10.1097/00005131-199707000-00003

28. Zwipp H, Rammelt $S$ and Barthel S. Calcaneal fracture - open reduction and internal fixation (ORIF). Injury. 2004; 35(Suppl 2): SB46-SB54

https://doi.org/10.1016/j.injury.2004.07.011

29. Christopher F. Hyer (Editor), Gregory C. Berlet (Editor), \& 3 more Essential Foot and Ankle Surgical Techniques: A Multidisciplinary Approach 1st ed. 2019 Edition ISBN-13: 978-3030147778 ISBN10: 3030147770

30. Kienast B, Gille J, Queitsch C, Kaiser MM, Thietje R, Juergens $\mathrm{C}$, et al. Early weight bearing of calcaneal fractures treated by intraoperative 3D-fluoroscopy and locked-screw plate fixation. Open Orthop J. 2009; 3:69-74 https://doi.org/10.2174/1874325000903010069

31. Houghton GR. Weight relieving cast for comminuted oscalcis fractures. A preliminary report. Injury. 1984; 16: 63-64. https://doi.org/10.1016/0020-1383(84)90122-0

\section{Authors Contribution:}

ARS, JA - Concept and Design of the study, prepared first draft of manuscript; VKS, PK- Interpretation of results, literature review; ARS, PK- Coordination,

review of literature, final manuscript preparation; ARS, PK- Statistical analysis and interpretation, final revision of manuscript

Work attributed to:

Mahamaya Rajkiya Allopathic Medical College, Ambedkar Nagar, Uttar Pradesh, India and Government Doon Medical college Dehradun.

Orcid ID:

Dr Pavneesh Kumar- (10 https://orcid.org/0000-0002-7576-2611

Source of Funding: None, Conflict of Interest: None. 